\title{
Robust Design of a Low-Cost Permanent Magnet Motor with Soft Magnetic Composite Cores Considering the Manufacturing Process and Tolerances
}

\author{
Chengcheng Liu ${ }^{1,2} \mathbb{D}^{\mathbb{D}}$, Gang $\mathrm{Lei}^{3, *(\mathbb{D})}, \mathrm{Bo} \mathrm{Ma}^{3}$, Youguang Guo ${ }^{3}$ and Jianguo $\mathrm{Zhu}^{4}$ \\ 1 School of Electrical and Electronic Engineering, Huazhong University of Science and Technology, \\ Wuhan 430074, China; 2016020@hebut.edu.cn \\ 2 State Key Laboratory of Reliability and Intelligence of Electrical Equipment, Hebei University of Technology, \\ Tianjin 300130, China \\ 3 School of Electrical and Data Engineering, University of Technology Sydney, Sydney, NSW 2007, Australia; \\ bo.ma@student.uts.edu.au (B.M.); Youguang.guo-1@uts.edu.au (Y.G.) \\ 4 School of Electrical and Information Engineering, The University of Sydney, Sydney, NSW 2000, Australia; \\ jianguo.zhu@sydney.edu.au \\ * Correspondence: gang.lei@uts.edu.au; Tel.: +61-2-9514-1268
}

Received: 3 July 2018; Accepted: 2 August 2018; Published: 3 August 2018

\begin{abstract}
This paper uses the Taguchi method to optimize the manufacturing process and robust design of a low-cost permanent magnet motor with soft magnetic composite (SMC) cores. For the manufacturing process, SMC cores are produced by using the molding technology without any wire cutting costs. To maximize the relative permeability and minimize the core loss, the Taguchi method is employed to identify the best control factor values for the heat treatment of SMC cores based on a series of experimental results. Due to the manufacturing tolerances, there are significant uncertainties in the core densities and motor dimensions, which will result in big performance variations for the SMC motors in the batch production. To obtain a robust design less sensitive to these tolerances, the conventional Taguchi parameter design method and a sequential Taguchi optimization method are presented to maximize the average torque and minimize the core loss of a low-cost PM motor. Through comparison, it is found that the proposed optimization method is efficient. It can provide an optimal design with better motor performance and manufacturing quality. The proposed method will benefit the industrial production of cost-effective PM-SMC motors with robust and compact designs.
\end{abstract}

Keywords: permanent magnet motor; soft magnetic composite; Taguchi method; manufacturing tolerances

\section{Introduction}

Soft magnetic composite (SMC), as a relatively new magnetic material, is a kind of iron powder made of fine particles (around $0.1 \mathrm{~mm}$ in diameter) with thin electrical insulation. Due to the powder nature, motor cores made of SMC have some advantages compared with cores made of silicon steel sheets, such as lower eddy current loss and isotropic electromagnetic and thermal properties. These advantages benefit the design of high-performance permanent magnet (PM) motors with 3D flux path, such as transverse flux machine, axial flux motor, linear brushless motor and claw pole motor [1-6].

Another important advantage of SMC cores is their low cost, including the manufacturing cost. The manufacturing process of SMC cores can be totally different from those cores made of steel sheets. Taking advantage of the powder metallurgy technology, the SMC cores can be produced by molding technology [1,7-9]. This kind of technology can be used to produce SMC cores with complex structures that may be hard or even impossible to manufacture by the traditional lamination method [10]. There 
are two main steps in this technology, powder compaction and heat treatment. In the first step, several stator/rotor core dies (made of tool steel) are employed to compact the SMC powder to form a 3D raw core by using a press. In the second step, the raw core will be cooked to complete the heat treatment process. The obtained SMC cores after the heat treatment can be used for the assembly directly. This kind of manufacturing method benefits the batch production of SMC cores and motors at low cost. This is very important for the low-cost applications of SMC motors, such as electric fans and compressors in air conditioners.

Regarding the low-cost applications of SMC motors, a major challenge is how to maintain good (at least satisfactory) performance and manufacturing quality of the motors with less material and manufacturing cost. Thus, there are two issues to address, low cost and good performance.

For the first issue, the cost of SMC motors mainly consists of two parts, material cost and manufacturing cost. High-performance NdFeB magnets have been used in many PM-SMC motors, such as transverse flux machine and axial flux motor to achieve good performance [1-9,11]. However, they are very expensive. To decrease the cost of SMC motors, ferrite magnets can be used to replace these expensive $\mathrm{NdFeB}$ magnets with a proper design of the motor topology, for example, the flux concentration design [12]. Meanwhile, transverse flux reluctance machine can be designed without the use of any magnets [1,13]. As this work focuses on the PM-SMC motors, ferrite magnets will be investigated in the following discussion. Regarding the manufacturing cost of PM-SMC motors, other parts except the SMC cores can be manufactured by the standard machining processes. For the manufacturing method of the SMC cores, there are two ways, wire cutting and molding technology. Wire cutting has been used for the manufacturing of SMC cores from big molded SMC blocks in most research work. Compared with the molding technology, wire cutting is expensive and small cracks can happen during the cutting process. These small cracks will affect the magnetic flux of the motors. Therefore, molding technology will be discussed in this work.

Regarding the molding technology for SMC cores, an important step is the heat treatment. This step cooks the raw core samples in a high-temperature furnace with several temperature control factors, such as the curing temperature and time. These control factors should be investigated and optimized to obtain an SMC core with good magnetic properties, such as higher permeability and lower core loss. To the best of the knowledge, this issue has not yet been investigated for the manufacturing of SMC cores for PM motors. To address it, the Taguchi method will be used to determine the best control factor values in this paper.

For the second issue, good performance and manufacturing quality of the SMC motors, they are related to the manufacturing tolerances. Due to the uncertain pressure employed in the powder compaction process, the densities of the SMC cores vary significantly, which will affect the magnetization curves of these cores and result in big variations to the motor performances [7-9]. There are some manufacturing tolerances for other parts of the PM-SMC motors as well, such as the dimension of the ferrite magnet and the length of the air gap. To obtain a robust motor design less sensitive to these variations, the SMC cores and the motor should be designed and optimized appropriately with the consideration of these manufacturing tolerances. In this work, the Taguchi parameter design method is first introduced to maximize the average torque and minimize the core loss of a low-cost PM-SMC motor. To further improve the motor performance, a sequential Taguchi optimization method will be presented as well.

The remainder of this paper is organized as follows: Section 2 introduces the structure and main dimensions of a PM-SMC motor that will be investigated in this work. Section 3 investigates the manufacturing process of the SMC cores with a focus on the heat treatment condition. The manufacturing tolerances of the SMC cores will be discussed as well. Section 4 conducts the optimization based on the Taguchi method and presents a new robust design method, sequential Taguchi optimization method, for the investigated PM-SMC motor. Section 5 compares the motor performances with different designs, followed by the conclusion. 


\section{Description for a PM-SMC Motor}

Figure 1 illustrates the one-phase structure of the investigated PM-SMC motor. This is a 3D-flux flux-switching permanent magnet motor (FSPMM). The whole motor consists of three phases and there is a shift of 120 electrical degrees for two phases [12]. As shown, SMC cores are designed for both the stator and rotor of this motor. The stator consists of two parts, SMC cores and ferrite magnets. The rotor is made of SMC only, without any magnets or windings. Thus, the rotor has a robust mechanical structure, like the rotor of a normal FSPMM with NdFeB magnets [14]. For the flux in this motor, it goes through the ferrite magnet in the circumferential direction, the stator teeth in radial direction and the rotor in the axial direction. This motor is designed to provide an output torque of $2 \mathrm{Nm}$ at rated speed $3600 \mathrm{rev} / \mathrm{min}$ for compressor application in a kind of air conditioner. Table 1 lists some main dimensions of this machine.

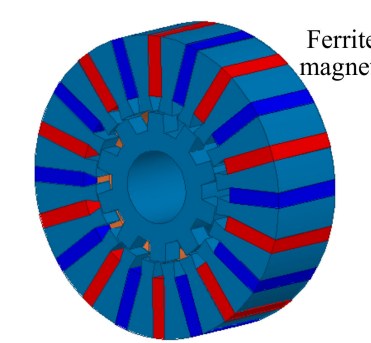

(a)

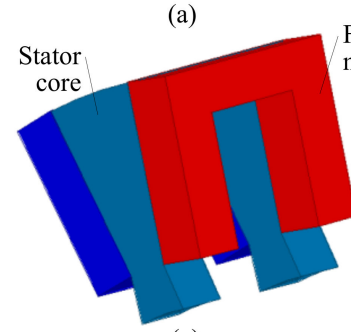

(c)

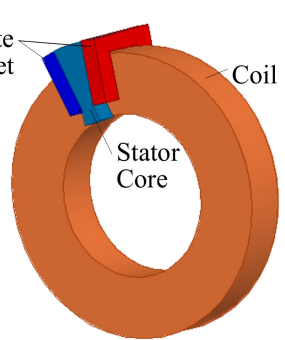

(b)

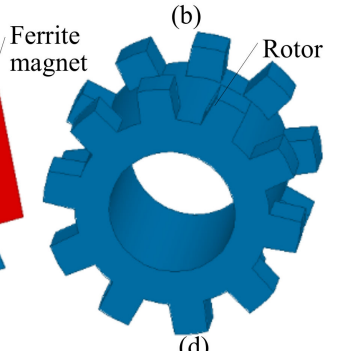

Figure 1. Structure of an FSPMM with SMC cores, (a) one-phase structure, (b) winding and magnets, (c) stator part, and (d) rotor part.

Table 1. Main dimensions of the FSPMM with SMC cores.

\begin{tabular}{cccc}
\hline Parameter & Symbol & Value & Unit \\
\hline Shaft radius & $R_{\text {shaft }}$ & 9.5 & $\mathrm{~mm}$ \\
\hline Stator outer radius & $R_{s o}$ & 50 & $\mathrm{~mm}$ \\
\hline Stator inner radius & $R_{s i}$ & 25 & $\mathrm{~mm}$ \\
\hline Height of stator yoke & $H_{s y}$ & 5 & $\mathrm{~mm}$ \\
\hline Slot angle of stator teeth & $\theta_{s t}$ & 4.5 & $\mathrm{deg}$ \\
\hline Air gap length & $L_{g a p}$ & 0.5 & $\mathrm{~mm}$ \\
\hline Effective axial length & $L_{a x i a l}$ & 31 & $\mathrm{~mm}$ \\
\hline Length of rotor teeth & $L_{r t}$ & 6 & $\mathrm{~mm}$ \\
\hline Angle of rotor pole & $\theta_{r p}$ & 15 & $\mathrm{deg}$ \\
\hline Width of magnet & $W_{p m}$ & 5 & $\mathrm{~mm}$ \\
\hline Number of turns & $N_{c}$ & 70 & turns \\
\hline
\end{tabular}

For the magnetic field analysis, the magnetostatic model of MAXWELL 3D with the default boundary is adopted. Figure 2 shows the mesh and no-load flux density distribution of this FSPMM obtained from Maxwell. The total number of mesh elements is 341,526. The flux density on the stator teeth is about 1.2 T, this is high considering that ferrite magnets are employed for the PM field excitation. 


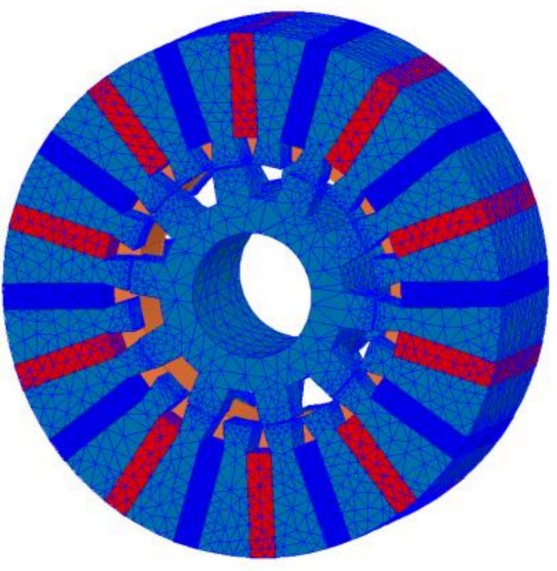

(a)

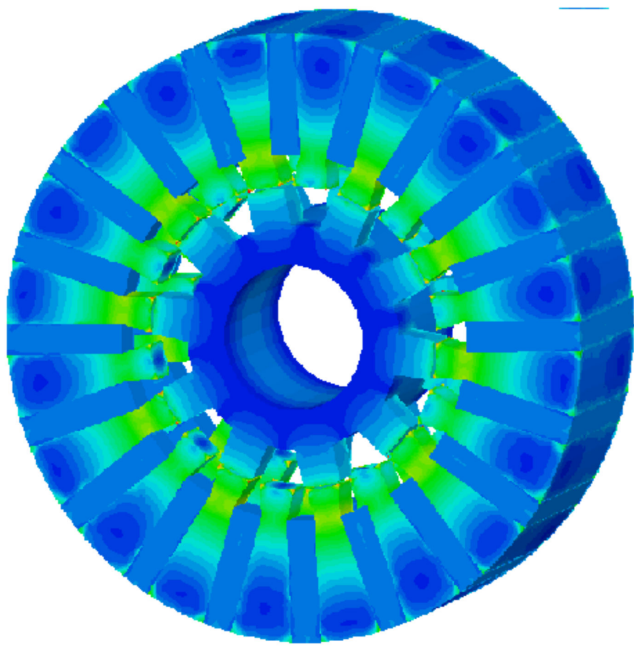

(b)

Figure 2. Mesh and no-load flux density distribution of the FSPMM. (a) Mesh for finite element analysis; (b) No-load flux density distribution.

\section{Manufacturing Process and Tolerances of the SMC Cores for the FSPMM}

\subsection{Manufacturing Process of the SMC Cores}

Figure 3 shows the manufacturing process and several manufactured SMC cores. There are two main steps in the manufacturing, powder compaction and heat treatment. In the first step, a hydraulic press (Figure 3d) is used to compact the SMC powder (Figure 3a) with several stator/rotor die tools (Figure $3 b, c$ ) to produce raw samples of the stator core (Figure 3g) and the rotor core (Figure 3i). In the second step, a high-temperature furnace (Figure $3 \mathrm{e}$ ) is employed to cook the raw cores to produce the finished stator core (Figure 3h) and rotor core (Figure 3j). Figure 3k,l show two other cooked rotor cores with different heat treatment conditions. Both steps will affect the magnetic properties of the cores. The first step can be done by a standard machining process. Due to the uncertain pressure applied to the compacted cores, there are significant variations in the core densities in the batch production of the SMC cores. The second step can be implemented by using an auto-control high-temperature furnace. Figure $3 \mathrm{f}$ shows the temperature control panel of the used furnace in our laboratory.

Compared with the compaction step, the heat treatment step has more significant influence on the magnetic property variations of the SMC cores as there are more control factors in this step. Figure $3 j-1$ show three cooked rotor cores obtained from different control factors for the heat treatment. As shown, they have different colours and the last one (Figure 31) usually is not good as it is black due to the break of electrical insulation at high temperature. Thus, they should have different magnetic properties. To determine the best heat treatment condition, the control factors involved in the heat treatment process will be investigated and optimized by using the Taguchi method in the next subsection. 


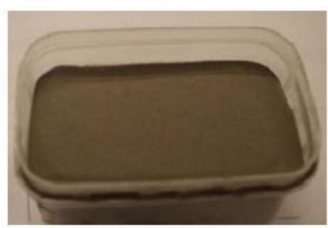

(a)

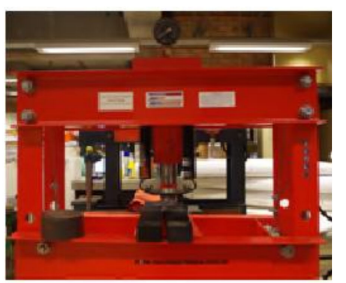

(d)

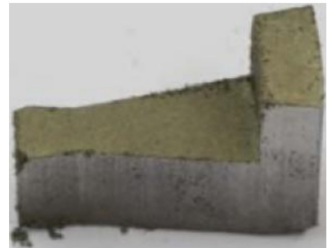

(g)

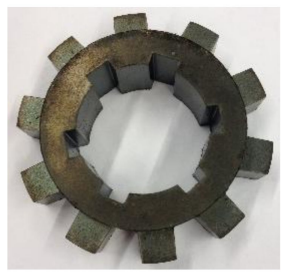

(j)

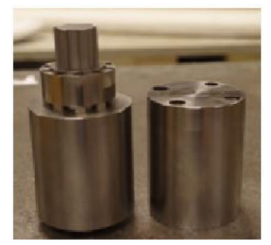

(b)

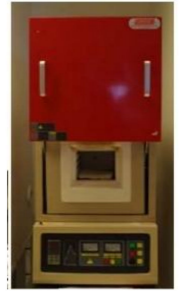

(e)

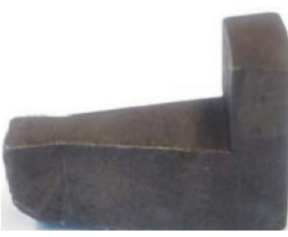

(h)

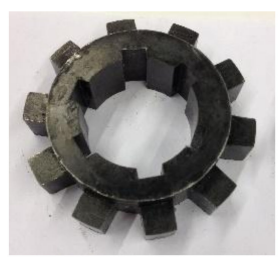

(k)

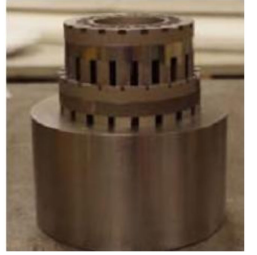

(c)

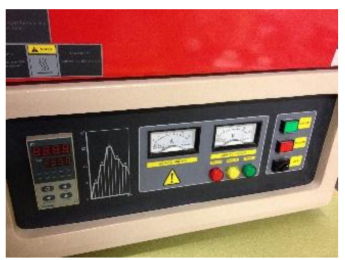

(f)

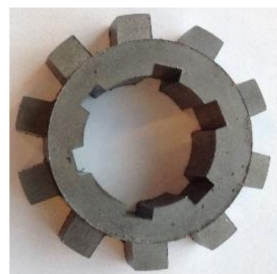

(i)

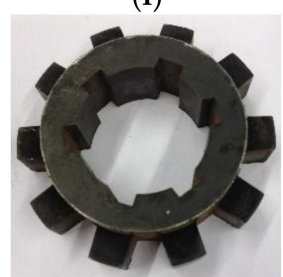

(1)

Figure 3. Facilities and SMC cores for the proposed FSPMM, (a) SMC powder, (b) die tools for compaction of the rotor core, (c) die tools for compaction of the stator cores, (d) a hydraulic press, (e) a high-temperature furnace, (f) the temperature control panel, (g) a raw stator core, (h) a cooked stator core after heat treatment, $(\mathbf{i})$ a raw stator core, $(\mathbf{j}-\mathbf{l})$ three stator cores after heat treatment.

\subsection{Analysis of the Best Heat Treatment Condition by Using Taguchi Method}

Figure 4 shows a proposed heat treatment process for the SMC cores. As shown, there are four main steps, warning up, burn-off and curing, relaxation and cooling. Five factors as listed in Table 2 are used to control this process. They are warming up temperature (Te1), burn-off and curing temperature (Te2) and time (Ti1), and relaxation temperature (Te3) and time (Ti2). Temperature $\mathrm{Te} 2$ aims to ensure the mechanical strength of the compacted SMC core. Temperature Te3 targets to eliminate the stress and improve the magnetic performance [9]. All these factors will affect the magnetic properties of the SMC cores, such as permeability and core loss. To identify the optimal values for these control factors, the Taguchi method will be investigated. Taguchi method has been widely employed in experimental designs for problems with multiple factors. By using orthogonal arrays, it is able to search in the parameter space with a small number of experiments [15-22].

Table 3 lists an orthogonal array to determine the best heat treatment condition for the SMC cores. As shown, only $18 \mathrm{SMC}$ cores are required for the analysis of magnetization curves and core losses of them. These magnetic properties are very important for the SMC cores and have been discussed in many research papers [1,22-24]. To conduct the experiment, 18 samples have been fabricated and three of them (the first three samples listed in Table 3) are shown in Figure 3. To determine their magnetic properties, all these samples are tested with an experimental platform as shown in Figure 5a. In the 
figure, the digital multimeter 1 (type: GDM-8045G, manufacturer: Good Will Instrument CO. LTD.) is used to measure the input current, the digital multimeter 2 (type: Agilent 34401A) is used to measure the input resistance for the calculation of copper loss, and the digital oscilloscope (type: Tektronix DPO 2024) is used to record the data of the magnetization curves.

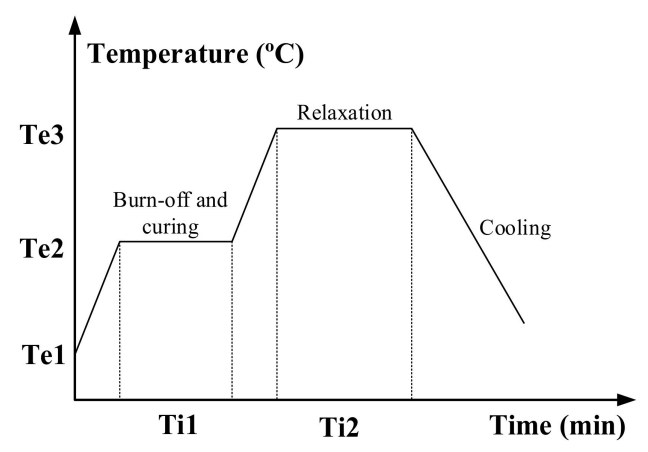

Figure 4. Heat treatment process for the SMC cores.

Table 2. Levels of control factors for the heat treatment of SMC cores.

\begin{tabular}{cccccc}
\hline \multirow{2}{*}{ Factor } & Description & \multirow{2}{*}{ Unit } & \multicolumn{3}{c}{ Levels } \\
\cline { 4 - 6 } & & & $\mathbf{1}$ & $\mathbf{2}$ & $\mathbf{3}$ \\
\hline $\mathrm{Te} 1$ & Warming up temperature & ${ }^{\circ} \mathrm{C}$ & 25 & 100 & 200 \\
$\mathrm{Te} 2$ & Burn-off and curing temperature & ${ }^{\circ} \mathrm{C}$ & 420 & 450 & 480 \\
$\mathrm{Ti} 1$ & Burn-off and curing time & $\min$ & 30 & 60 & 90 \\
$\mathrm{Te} 3$ & Relaxation temperature & ${ }^{\circ} \mathrm{C}$ & 500 & 550 & 600 \\
$\mathrm{Ti} 2$ & Relaxation time & $\mathrm{min}$ & 10 & 30 & 50 \\
\hline
\end{tabular}

Table 3. An orthogonal array and experimental results for the heat treatment of SMC cores.

\begin{tabular}{ccccccccc}
\hline No. & Te1 & Te2 & Ti1 & Te3 & Ti2 & $\mu_{r}$ & Core Loss & Objective $(y)$ \\
\hline 1 & 1 & 1 & 1 & 1 & 1 & 210.72 & 10.87 & 1.45 \\
\hline 2 & 1 & 2 & 2 & 2 & 2 & 239.76 & 14.73 & 1.43 \\
\hline 3 & 1 & 3 & 3 & 3 & 3 & 192.10 & 66.21 & 3.24 \\
\hline 4 & 2 & 1 & 1 & 2 & 2 & 243.34 & 67.48 & 3.02 \\
\hline 5 & 2 & 2 & 2 & 3 & 3 & 197.12 & 70.42 & 3.33 \\
\hline 6 & 2 & 3 & 3 & 1 & 1 & 261.68 & 7.56 & 1.13 \\
\hline 7 & 3 & 1 & 2 & 1 & 3 & 249.63 & 5.71 & 1.12 \\
\hline 8 & 3 & 2 & 3 & 2 & 1 & 265.92 & 14.57 & 1.33 \\
\hline 9 & 3 & 3 & 1 & 3 & 2 & 206.15 & 67.48 & 3.19 \\
\hline 10 & 1 & 1 & 3 & 3 & 2 & 222.22 & 48.72 & 2.54 \\
\hline 11 & 1 & 2 & 1 & 1 & 3 & 273.33 & 7.42 & 1.09 \\
\hline 12 & 1 & 3 & 2 & 2 & 1 & 274.41 & 15.13 & 1.32 \\
\hline 13 & 2 & 1 & 2 & 3 & 1 & 202.56 & 83.40 & 3.69 \\
\hline 14 & 2 & 2 & 3 & 1 & 2 & 226.28 & 5.94 & 1.22 \\
\hline 15 & 2 & 3 & 1 & 2 & 3 & 250.75 & 14.90 & 1.39 \\
\hline 16 & 3 & 1 & 3 & 2 & 3 & 271.49 & 13.59 & 1.28 \\
\hline 17 & 3 & 2 & 1 & 3 & 1 & 183.11 & 74.40 & 3.54 \\
\hline 18 & 3 & 3 & 2 & 1 & 2 & 267.10 & 4.48 & 1.02 \\
\hline & & & & & & & &
\end{tabular}

Figure $5 b-d$ show the measured magnetization curves (with hysteresis loops) for the first three samples listed in Table 3. Meanwhile, a clamp meter (type: Fluke 345) is used to measure the input power. Based on the experimental results, the values of relative permeability $\left(\mu_{r}\right)$ and core loss (unit: $\mathrm{W} / \mathrm{kg}$ ) of these 18 samples can be estimated, as listed in Table 3. 


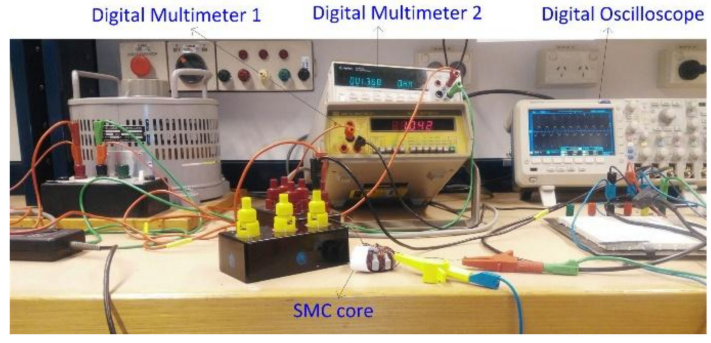

(a)

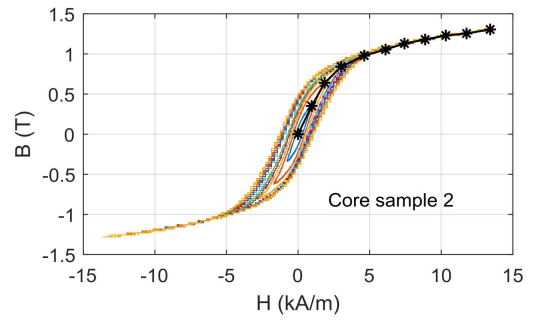

(c)

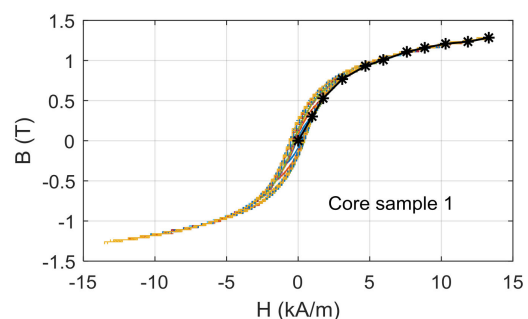

(b)

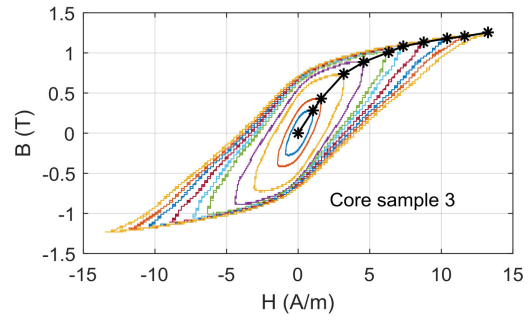

(d)

Figure 5. (a) An experimental platform for SMC cores, (b-d) measured magnetization curves for cores $1-3$.

To identify the best combination of the control factor values (or levels), an objective function is defined as follows to maximize the relative permeability and minimize the core loss $\left(P_{\text {core }}\right)$ :

$$
y(i)=\frac{\mu_{r \_a v e}}{\mu_{r}(i)}+\frac{P_{\text {core }}(i)}{P_{\text {core_ave }}}
$$

where $i(1,2, \ldots, 18)$ is the number of experiments, and the subscript ave means average. To identify the best level of each control factor, averages of the relative permeability, core loss and objective are calculated for all control factors, as listed in Table 4. As an example to show the calculation method, the average objective for the level 1 of factor Te3 is computed as follows:

$$
y_{\text {ave }}(\mathrm{Te} 3, \text { level1 })=\frac{y(1)+y(6)+y(7)+y(11)+y(14)+y(18)}{6}=1.17,
$$

where 1, 6, 7, 11, 14 and 18 are the numbers of experiments with 1 as the level of the factor Te3, as listed in Table 3.

Table 4. Averages of motor performance and design objectives for all control factors.

\begin{tabular}{ccccc}
\hline Factor & Level & $\boldsymbol{\mu}_{\boldsymbol{r}}$ & Core loss & Objective $(y)$ \\
\hline \multirow{3}{*}{ Te1 } & 1 & 235.42 & 27.18 & 1.84 \\
& 2 & 230.29 & 41.62 & 2.30 \\
& 3 & 240.57 & 30.04 & 1.91 \\
\hline \multirow{3}{*}{ Tr2 } & 1 & 233.33 & 38.30 & 2.18 \\
& 2 & 230.92 & 31.25 & 1.99 \\
& 3 & 242.03 & 29.29 & 1.88 \\
\hline \multirow{2}{*}{ Ti1 } & 1 & 227.90 & 40.43 & 2.28 \\
& 2 & 238.43 & 32.31 & 1.98 \\
& 3 & 239.95 & 26.10 & 1.79 \\
\hline \multirow{3}{*}{ Te3 } & 1 & 248.12 & 7.00 & 1.17 \\
& 2 & 257.61 & 23.40 & 1.63 \\
& 3 & 200.54 & 68.44 & 3.26 \\
\hline \multirow{2}{*}{ Ti2 } & 1 & 233.07 & 34.32 & 2.08 \\
& 2 & 234.14 & 34.81 & 2.07 \\
\hline
\end{tabular}


According to the Taguchi method, the level that can provide the smallest objective should be chosen as the best level for each factor [15-22]. To clearly show the selection process, Figure 6 shows the average objectives for all levels of those five factors. As shown, the best combination of the control factor levels is $1,3,3,1,3$.

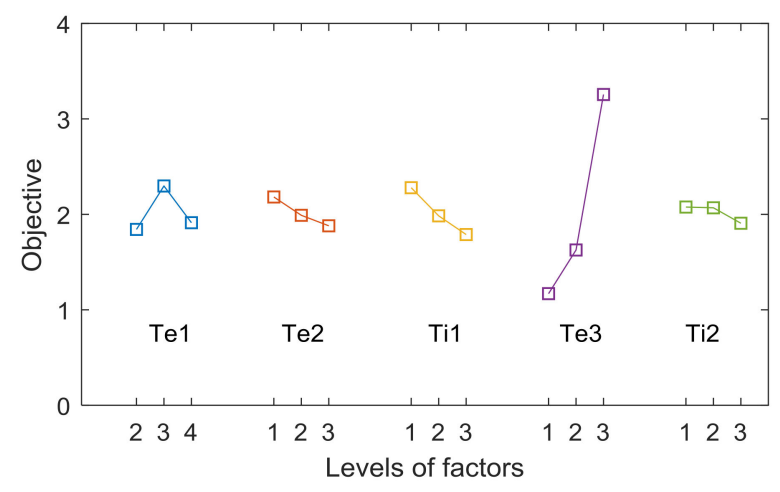

Figure 6. Average objectives for all factors.

In addition, as shown in Figure 6, the fourth factor (Te3) has the highest influence on the magnetic properties of these SMC cores as its average varies significantly in terms of different design levels. The best level for this factor is 1 , meaning that the relaxation temperature should be $500{ }^{\circ} \mathrm{C}$. If the temperature is over $500{ }^{\circ} \mathrm{C}$, the electrical insulation of the iron powder may be destroyed, which will result in bigger core loss.

\subsection{Variations of the Core Densities and Magnetization Curves}

It is found that there are significant variations in the core densities. Figure 7a shows the measured core densities for those SMC cores. As shown, the standard deviation (STD) of the densities is $0.05 \mathrm{~g} / \mathrm{cm}^{3}$. These variations will affect the magnetization curves of SMC cores. Figure $7 \mathrm{~b}$ illustrates three magnetization curves for three different core densities in the range of [6.77 7.07]. The difference between the mean core density $\left(6.92 \mathrm{~g} / \mathrm{cm}^{3}\right)$ and the lower/upper boundary of the range is $0.15 \mathrm{~g} / \mathrm{cm}^{3}$ (three times of the STD). As shown, significant differences can be observed, which will result in big variations for the magnetic field distribution in the motor, and consequently, the motor performance.

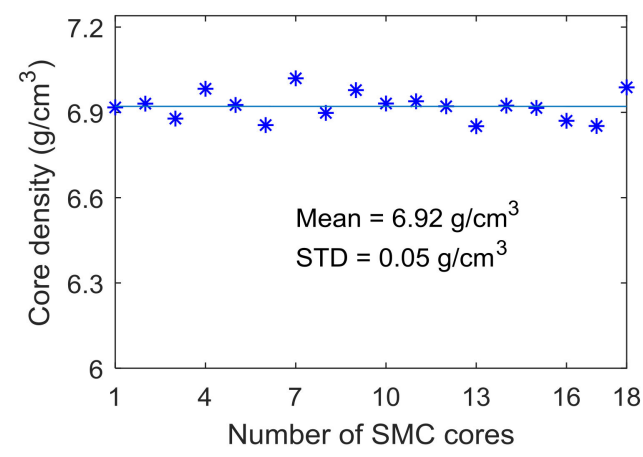

(a)

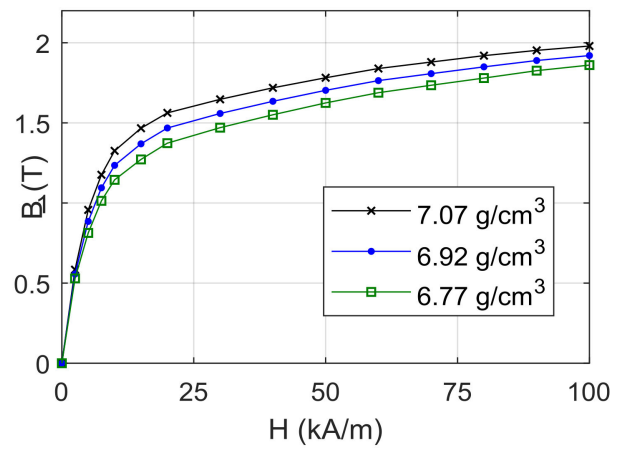

(b)

Figure 7. (a) SMC core density variation, (b) magnetization curves vs core densities.

Therefore, to improve the performance and manufacturing quality of the investigated FSPMM, robust design optimization is needed and will be discussed in the next section. 


\section{Motor Performance Optimization by Using Taguchi Method}

\subsection{Taguchi Parameter Design Method}

In general, to improve the performance of electrical machines, many optimization methods can be employed, such as the intelligent optimization algorithms, multilevel, multiobjective and multidisciplinary optimization methods [25-33]. For the optimization of the investigated FSPMM under manufacturing variations, this is a kind of robust design optimization problem. To solve this problem, Taguchi parameter design, worst case design and design for six-sigma (DFSS) are three normally used methods [26,32-38]. Among them, Taguchi parameter design method requires the least simulation cost.

For the investigated FSPMM, 3D finite element model (FEM) as shown in Figure 2a is required as this is a $3 \mathrm{D}$ flux machine. The simulation time of one design with Maxwell is around $25 \mathrm{~min}$ on a PC with $3.2 \mathrm{GHz}$ CPU and $8 \mathrm{~GB}$ RAM. This is a huge computation cost if several thousand FEM samples are required. Therefore, to decrease the computation cost, the Taguchi parameter design method will be employed to optimize the investigated FSPMM in this work. In the implementation, two types of factors, control and noise factors, are required to define for this motor. The control factors are the design parameters that will be optimized, whereas the noise factors are parameters that characterize the manufacturing tolerances. An orthogonal array consisting of an inner array and an outer array will be generated to conduct the simulations. Based on that, the signal/noise $(\mathrm{S} / \mathrm{N})$ ratio, as an index of motor quality, is used to determine the best combination of the control factor values that make the motor robust to those manufacturing tolerances [34-38].

For this motor, five parameters $\left(\theta_{s t}, L_{g a p}, L_{r t}, W_{p m}\right.$, and $\left.\theta_{r p}\right)$ as shown in Figure 8 are crucial to its performance, where $W_{p m}$ is the width of the ferrite magnet in the direction of magnetization, $L_{\text {gap }}$ is the length of the air gap, and the others are three parameters for SMC cores. Table 5 lists the initial design ranges of them. These parameters are considered as the control factors for the Taguchi parameter design of this motor. Table 6 tabulates the levels for these five control factors. As shown, each factor has four levels. Table 7 lists three noise factors and their levels. These factors are related to the manufacturing tolerances of the ferrite magnets, SMC cores and the air gap. They account for the main performance variations for this FSPMM, and they are hard to control in the manufacturing. As listed in the table, each noise factor has two levels. For example, the two levels for the core density $(\rho)$ are -0.15 and $0.15 \mathrm{~g} / \mathrm{cm}^{3}$, meaning that the practical core densities in the manufacturing are 6.77 and $7.07 \mathrm{~g} / \mathrm{cm}^{3}$, respectively. They are calculated by $6.92-0.15$ and $6.92+0.15$, respectively, where 6.92 is the core density of the initial design.

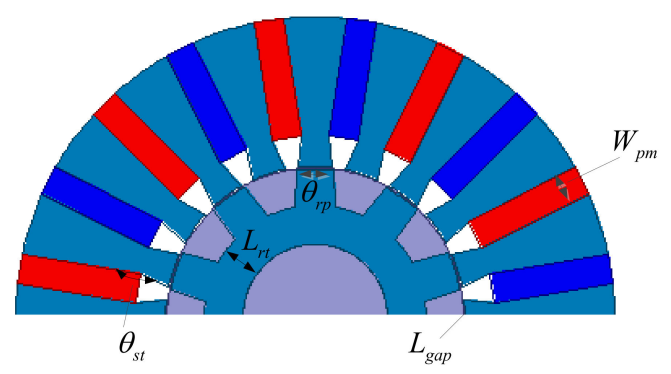

Figure 8. Design parameters for the FSPMM.

Based on these control and noise factors, Table 8 lists an orthogonal array for the robust design and analysis of this motor. As shown, there are 16 rows, meaning that 16 combinations of the control factors are required to form the inner array. For the noise factors, four combinations are needed to form the outer array, and they are listed as 111, 122, 212 and 221 in the table. 1 or 2 means the level of the control factor. For example, 122 represents the combination of levels 1, 2, and 2 for these three noise factors, respectively. Therefore, $64(16 \times 4)$ combinations (FEM samples) will be required for the simulation in Maxwell. Table 8 lists the average torques and core losses of these 64 samples. 
Table 5. Design parameters and ranges for the FSPMM.

\begin{tabular}{cccc}
\hline Control Factor & Unit & $\min$ & $\max$ \\
\hline$\theta_{s t}$ & $\mathrm{deg}$ & 4 & 7 \\
\hline$L_{g a p}$ & $\mathrm{~mm}$ & 0.45 & 0.75 \\
\hline$L_{r t}$ & $\mathrm{~mm}$ & 5 & 8 \\
\hline$W_{p m}$ & $\mathrm{~mm}$ & 4 & 7 \\
\hline$\theta_{r p}$ & $\mathrm{deg}$ & 10 & 17 \\
\hline
\end{tabular}

Table 6. Control factors and levels for the FSPMM.

\begin{tabular}{cccccc}
\hline \multirow{2}{*}{ Control Factor } & \multirow{2}{*}{ Unit } & \multicolumn{4}{c}{ Levels } \\
\cline { 3 - 6 } & & $\mathbf{1}$ & $\mathbf{2}$ & $\mathbf{3}$ & $\mathbf{4}$ \\
\hline$\theta_{s t}$ & $\mathrm{deg}$ & 4.5 & 5 & 5.5 & 6 \\
\hline$L_{g a p}$ & $\mathrm{~mm}$ & 0.45 & 0.5 & 0.55 & 0.6 \\
\hline$L_{r t}$ & $\mathrm{~mm}$ & 5.5 & 6 & 6.5 & 7 \\
\hline$W_{p m}$ & $\mathrm{~mm}$ & 5 & 5.5 & 6 & 6.5 \\
\hline$\theta_{r p}$ & $\mathrm{deg}$ & 12 & 13 & 14 & 15 \\
\hline
\end{tabular}

Table 7. Noise factors and levels for the FSPMM.

\begin{tabular}{cccc}
\hline \multirow{2}{*}{ Noise Factor } & \multirow{2}{*}{ Unit } & \multicolumn{2}{c}{ Levels } \\
\cline { 3 - 4 } & & $\mathbf{1}$ & $\mathbf{2}$ \\
\hline$\Delta \rho$ & $\mathrm{g} / \mathrm{cm}^{3}$ & -0.15 & +0.15 \\
\hline$\Delta L_{g a p}$ & $\mathrm{~mm}$ & -0.05 & +0.05 \\
\hline$\Delta L W_{p m}$ & $\mathrm{~mm}$ & -0.05 & +0.05 \\
\hline
\end{tabular}

Table 8. An orthogonal array for the output torques and core losses of the FSPMM.

\begin{tabular}{|c|c|c|c|c|c|c|c|c|c|c|c|c|c|}
\hline \multirow[t]{2}{*}{ No. } & \multicolumn{5}{|c|}{ Control Factor Levels } & \multicolumn{4}{|c|}{$\begin{array}{l}\text { Noise Factor Levels and } \\
\text { Values for Torque }\end{array}$} & \multicolumn{4}{|c|}{$\begin{array}{l}\text { Noise Factor Levels and Values for } \\
\text { Core Loss }\end{array}$} \\
\hline & 1 & 2 & 3 & 4 & 5 & 111 & 122 & 212 & 221 & 111 & 122 & 212 & 221 \\
\hline 1 & 1 & 1 & 1 & 1 & 1 & 2.08 & 2.08 & 2.42 & 2.42 & 117.31 & 116.16 & 130.21 & 128.92 \\
\hline 2 & 1 & 2 & 2 & 2 & 2 & 1.88 & 1.87 & 2.10 & 2.09 & 110.54 & 109.27 & 123.48 & 121.81 \\
\hline 3 & 1 & 3 & 3 & 3 & 3 & 1.72 & 1.70 & 1.93 & 1.91 & 102.81 & 101.45 & 114.75 & 113.25 \\
\hline 4 & 1 & 4 & 4 & 4 & 4 & 1.56 & 1.53 & 1.70 & 1.67 & 93.57 & 92.10 & 105.03 & 103.43 \\
\hline 5 & 2 & 1 & 2 & 3 & 4 & 1.93 & 1.91 & 2.09 & 2.06 & 111.77 & 110.23 & 124.41 & 122.73 \\
\hline 6 & 2 & 2 & 1 & 4 & 3 & 1.71 & 1.68 & 1.92 & 1.89 & 99.49 & 97.786 & 110.41 & 108.56 \\
\hline 7 & 2 & 3 & 4 & 1 & 2 & 1.82 & 1.82 & 2.05 & 2.06 & 109.12 & 108.16 & 122.84 & 121.77 \\
\hline 8 & 2 & 4 & 3 & 2 & 1 & 1.80 & 1.79 & 2.13 & 2.12 & 100.97 & 99.91 & 112.55 & 111.35 \\
\hline 9 & 3 & 1 & 3 & 4 & 2 & 1.82 & 1.79 & 2.01 & 1.97 & 96.68 & 95.19 & 108.43 & 106.77 \\
\hline 10 & 3 & 2 & 4 & 3 & 1 & 1.88 & 1.86 & 2.22 & 2.20 & 97.31 & 96.12 & 109.33 & 108.00 \\
\hline 11 & 3 & 3 & 1 & 2 & 4 & 1.90 & 1.89 & 2.05 & 2.04 & 114.43 & 113.03 & 126.51 & 124.97 \\
\hline 12 & 3 & 4 & 2 & 1 & 3 & 1.81 & 1.80 & 2.02 & 2.01 & 113.42 & 112.34 & 125.83 & 124.61 \\
\hline 13 & 4 & 1 & 4 & 2 & 3 & 1.98 & 1.97 & 2.20 & 2.19 & 110.23 & 109.07 & 123.84 & 122.55 \\
\hline 14 & 4 & 2 & 3 & 1 & 4 & 2.00 & 2.00 & 2.16 & 2.15 & 118.81 & 117.71 & 132.61 & 131.38 \\
\hline 15 & 4 & 3 & 2 & 4 & 1 & 1.74 & 1.72 & 2.07 & 2.04 & 90.50 & 89.02 & 100.66 & 99.036 \\
\hline 16 & 4 & 4 & 1 & 3 & 2 & 1.75 & 1.73 & 1.93 & 1.90 & 98.55 & 97.16 & 108.05 & 106.46 \\
\hline
\end{tabular}

For the performance optimization of this motor, there are two objectives, maximizing the average torque $\left(T_{\text {ave }}\right)$ and minimizing the core loss $\left(P_{\text {core }}\right)$. Based on them, an objective function is defined as follows to determine the best combination of control factor values:

$$
y(i, j)=\frac{T_{\text {ave_initial }}}{T_{\text {ave }}(i, j)}+\frac{P_{\text {core }}(i, j)}{P_{\text {core_initial }}},
$$


where $i(1,2, \ldots, 16)$ and $j(1,2,3,4)$ are the numbers of experiments for the inner and outer arrays, respectively. Table 9 lists the $\mathrm{S} / \mathrm{N}$ ratios for all 16 rows of the control factors. The calculation method can be briefly summarized as follows:

First, use (3) to compute the objective of all 64 samples listed in Table 8.

Second, calculate the $\mathrm{S} / \mathrm{N}$ ratio for each row in the table. According to the Taguchi parameter design method (with a target as the smaller the better), the calculation equation is:

$$
S N(i)=-10 \times \lg \left[\frac{1}{4} \times \sum_{j=1}^{4} y^{2}(i, j)\right] .
$$

Third, compute the average $\mathrm{S} / \mathrm{N}$ ratio for each level of all control factors. For example, for the third level of the second control factor $L_{g a p}$, it average $\mathrm{S} / \mathrm{N}$ ratio can be calculated by:

$$
R\left(\text { factor }=L_{g a p}, \text { level }=3\right)=\frac{S N(3)+S N(7)+S N(11)+S N(15)}{4},
$$

the numbers 3, 7, 11 and 15 can be found from the orthogonal array.

To identify the best combination of the control factor values, Figure 9 illustrates the average S/N ratios for all five factors. The best level of each factor can be obtained by selecting a level with the highest $\mathrm{S} / \mathrm{N}$ ratio. As shown, levels 4, 1, 4, 3, and 1 should be chosen for these five control factors, respectively. Their corresponding values can be found from Table 6 .

Table 9. S/ $\mathrm{N}$ ratios of the objective for the 16 experiments of the control factors.

\begin{tabular}{cccccccc}
\hline No. & SN/dB & No. & SN/dB & No. & SN/dB & No. & SN/dB \\
\hline $\mathbf{1}$ & -5.33 & $\mathbf{5}$ & -5.62 & $\mathbf{9}$ & -5.32 & $\mathbf{1 3}$ & -5.40 \\
\hline $\mathbf{2}$ & -5.62 & $\mathbf{6}$ & -5.67 & $\mathbf{1 0}$ & -5.03 & $\mathbf{1 4}$ & -5.73 \\
\hline $\mathbf{3}$ & -5.77 & $\mathbf{7}$ & -5.71 & $\mathbf{1 1}$ & -5.77 & $\mathbf{1 5}$ & -5.09 \\
\hline $\mathbf{4}$ & -6.03 & $\mathbf{8}$ & -5.35 & $\mathbf{1 2}$ & -5.90 & $\mathbf{1 6}$ & -5.53 \\
\hline
\end{tabular}

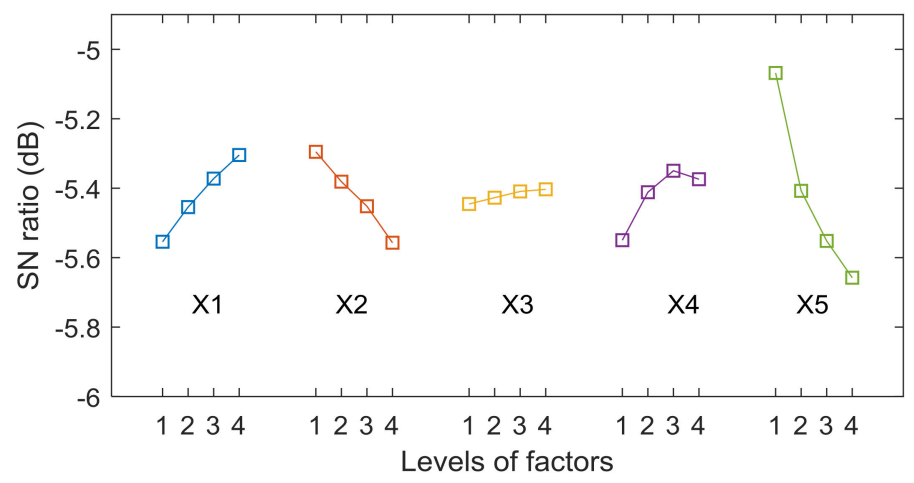

Figure 9. S/N ratios for each level of all factors.

\subsection{Sequential Taguchi Optimization Method}

For the optimal design obtained from Taguchi parameter design, the motor average torque is torque $2.01 \mathrm{Nm}$ and core loss is $104.07 \mathrm{~W}$. They are better than those of the initial design $(2.00 \mathrm{Nm}$ and 129.24 W). However, the improvements are not significant. The main reason is that only 64 samples and 4 levels have been considered for the control factors in the optimization process. There are big step sizes for different levels. To overcome this disadvantage and further improve the motor performance, a sequential Taguchi optimization method (STOM) is proposed as follows. Figure 10 illustrates the flowchart of the proposed STOM. There are five main steps: 
Step 1: Problem definition. This step defines the design objectives, control and noise factors of the motor.

Step 2: Taguchi parameter design. This step conducts the analysis of the Taguchi parameter design discussed in Section 4.1. First, define an orthogonal array for the control and noise factors. Second, simulate the motor performance. Third, calculate the $\mathrm{S} / \mathrm{N}$ ratios of each factor at different levels and determine the best level combination.

Step 3: Motor performance evaluation. This step evaluates the motor performance of the obtained optimal design, including average torque and core loss, and calculates the objective.

Step 4: Determination of the convergence. Compare the objectives obtained from this step and the last step. If the relative error is less than $\varepsilon$ (a positive value like $1 \%$ ), terminate the optimization process and output the optimal design. Otherwise, go to next step.

Step 5: Updating the design space. For most engineering optimization problems, the optimal point should be located in a small subspace compared with the initial big design space. Therefore, if that subspace can be found, the optimum should be better than the initial one. Following this idea, the design space will be reduced in this step by using a sequential optimization strategy $[39,40]$. In the implementation, the step size of each control factor will be halved in this step. For example, for the fourth control factor $\left(W_{p m}\right)$, the best level is 3 given by the Taguchi design, meaning that its value is $6 \mathrm{~mm}$. As the initial step size is $0.5 \mathrm{~mm}$, the next one is $0.25 \mathrm{~mm}$. Thus, the next four levels of this control factor will be $5.625,5.875,6.125$ and 6.375 , respectively. As shown, 6 is the mean of the second and third levels (mean of 5.875 and 6.125). If the best level is the lower or upper limit of the design space, the next design levels will start from or end with that level. For example, for the second control factor $\left(L_{g a p}\right)$, the best level is 1 given by the Taguchi design. Its value is $0.45 \mathrm{~mm}$, which is the lower limit of its design space. Therefore, the next four levels will start from it and the step size for any two levels is $0.025 \mathrm{~mm}$, and they are $0.45,0.475,0.5$ and 0.525 , respectively. Based on these updated design levels, the Taguchi parameter design should be conducted again until the convergence criterion is met.

Figure 11 shows the objectives obtained from the proposed STOM with $\varepsilon=1 \%$. As shown, four Taguchi parameter design processes $(k=1,2,3,4)$ are required for the proposed optimization method. The objectives for these design processes are 1.800, 1.657, 1.631, and 1.627 respectively. Meanwhile, a total of 256 samples are required for the performance simulation as 64 FEM samples are needed for each design process. Therefore, this method is efficient. The detailed optimal control factors and motor performance will be given in the next section.

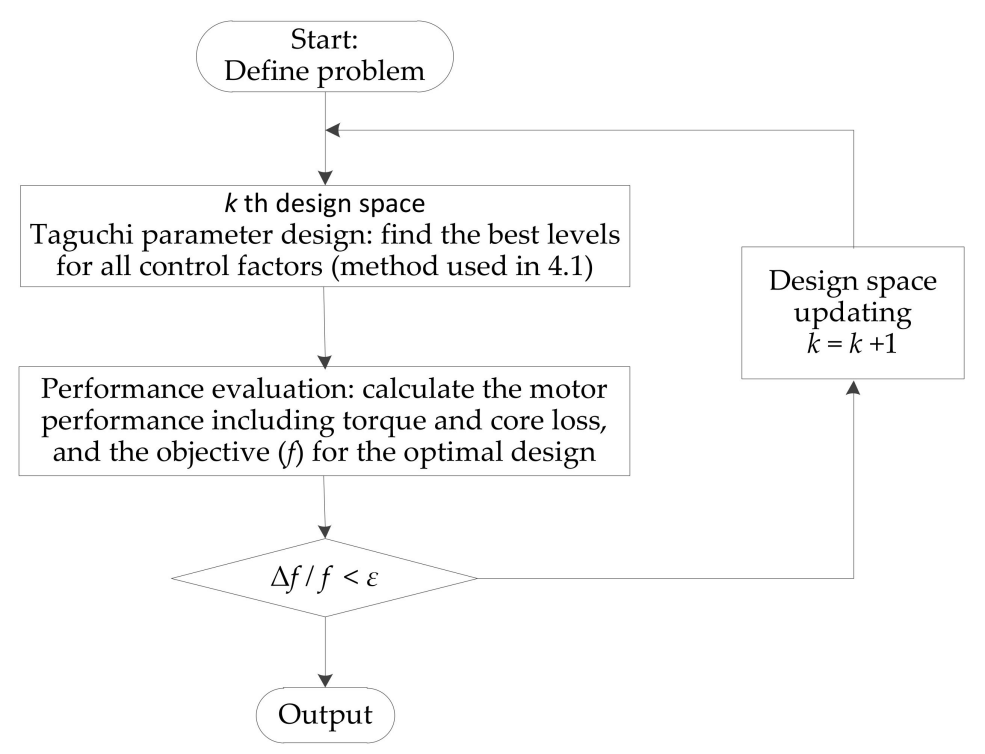

Figure 10. Flowchart of the sequential Taguchi optimization method. 


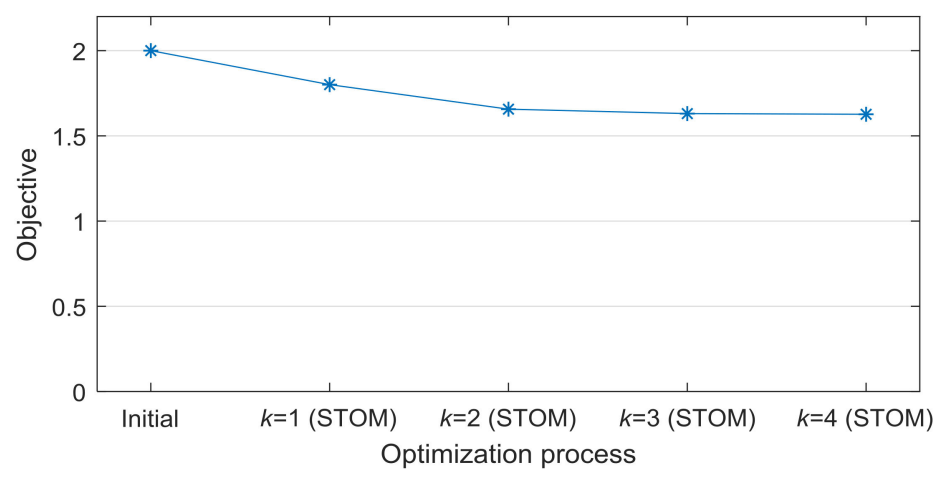

Figure 11. Optimization process of the sequential Taguchi optimization method.

\section{Comparison of Motor Performance with Different Designs}

Table 10 lists the optimal parameter values and the corresponding motor performance given by four different designs. Figures 12 and 13 compare the curves of the motor torque and core loss for these designs. The first one is the initial design. The second one is the optimal design provided by the Taguchi parameter design as discussed in Section 4.1. The third one is the optimal design given by the proposed STOM as discussed in Section 4.2. The last one is obtained from the DFSS method based on the following robust optimization model:

$$
\begin{array}{cl}
\min : & \mu_{f}(\mathbf{x}) \\
\text { s.t. } & g_{i}\left[\mu_{f}(\mathbf{x}), \sigma_{f}(\mathbf{x})\right] \leq 0, i=1,2
\end{array}
$$

where $f(\mathbf{x})=\frac{T_{\text {ave } i n i t i a l}}{T_{\text {ave }}(\mathbf{x})}+\frac{P_{\text {core }}(\mathbf{x})}{P_{\text {core_initial }}}$ is an objective function for the deterministic optimization model, $g_{1}(\mathbf{x})$ and $g_{2}(\mathbf{x})$ are two constraints, and given by $g_{1}(\mathbf{x})=2-T_{\text {ave }}(\mathbf{x}) \leq 0, g_{2}(\mathbf{x})=P_{\text {core }}(\mathbf{x})-130 \leq 0$, $\mathbf{x}$ is a vector of the five parameters listed in Table $5, \mu$ and $\sigma$ are the mean and standard deviation of the corresponding terms which are estimated by using the Monte Carlo analysis method. DFSS is a popular robust design method and has been successfully employed for the robust design optimization of PM-SMC motors $[25,26,32,33]$. The following conclusions can be drawn from the table and figures.

Firstly, the average torque and core loss given by the Taguchi parameter design are $2.01 \mathrm{Nm}$ and 104.07 W, respectively, which are better than those of the initial design (2.00 Nm and $129.24 \mathrm{~W})$. However, they are obviously worse than those of the STOM (2.25 Nm and 95.28 W) and DFSS $(2.20 \mathrm{Nm}$ and $91.02 \mathrm{~W}$ ). Compared with the initial and Taguchi designs, the motor's average torque given by the optimal STOM design has been increased by $12.5 \%$ and $12.0 \%$, respectively, while the core loss has been decreased by $26.28 \%$ and $8.44 \%$, respectively. Regarding the objective, the value of STOM is 1.63 , which is lower than those of the initial design (2.00) and Taguchi design (1.80), but is slightly higher than that of the DFSS (1.61). The difference between STOM and DFSS is small as the relative error is only $1.23 \%$.

Secondly, considering the computation cost, the required FEM samples will be compared as the FEM simulation accounts for the most computation time of this motor. The Taguchi and STOM designs require 64 and 256 FEM samples, respectively. However, DFSS requires about $9375\left(3 \times 5^{5}=9375\right)$ FEM samples if a surrogate model is employed with 5 levels for each of the five control parameters and 3 levels for the noise factor of core density. The computation cost of the STOM is only about $2.73 \%$ of that required by the DFSS. Therefore, the proposed STOM is efficient.

Thirdly, regarding the material cost of the ferrite PMs and SMC, the cost required by the STOM design is AUD 9.66, which is higher than those needed by the initial design (AUD 8.70) and the Taguchi design (AUD 9.57), and slightly lower than that required by the DFSS (AUD 9.83). However, the differences between them are small, and all are less than AUD 10.00. This confirms the low cost of this kind of motor. 
Table 10. Performance comparison for FSPMM with four designs.

\begin{tabular}{cccccc}
\hline Parameter & Unit & Initial & Taguchi & STOM & DFSS \\
\hline$\theta_{s t}$ & $\mathrm{deg}$ & 4.5 & 6 & 6.66 & 7.0 \\
\hline$L_{g a p}$ & $\mathrm{~mm}$ & 0.5 & 0.45 & 0.45 & 0.45 \\
\hline$L_{r t}$ & $\mathrm{~mm}$ & 6 & 5.5 & 7.53 & 7.50 \\
\hline$W_{p m}$ & $\mathrm{~mm}$ & 5 & 5.5 & 6.16 & 6.34 \\
\hline$\theta_{r p}$ & $\mathrm{deg}$ & 15 & 12 & 10.69 & 10.50 \\
\hline Torque & $\mathrm{Nm}$ & 2.00 & 2.01 & 2.25 & 2.20 \\
\hline Core loss & $\mathrm{W}$ & 129.24 & 104.07 & 95.28 & 91.02 \\
\hline Objective & - & 2.00 & 1.80 & 1.63 & 1.61 \\
\hline Ferrite PM cost & AUD & 6.09 & 7.31 & 7.50 & 7.72 \\
\hline SMC cost & AUD & 2.61 & 2.26 & 2.16 & 2.11 \\
\hline Cost (PM + SMC) & AUD & 8.70 & 9.57 & 9.66 & 9.83 \\
\hline FEM samples & - & - & 64 & 256 & 9375 \\
\hline & & & & &
\end{tabular}

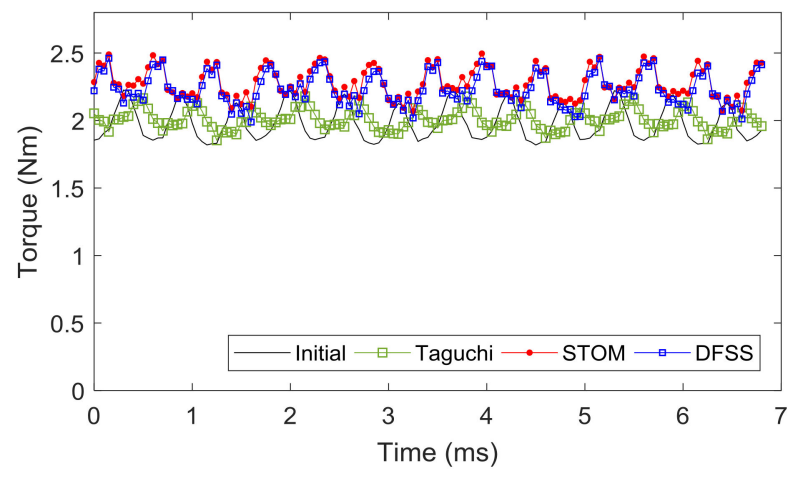

Figure 12. Torque curves for the FSPMM with four designs.

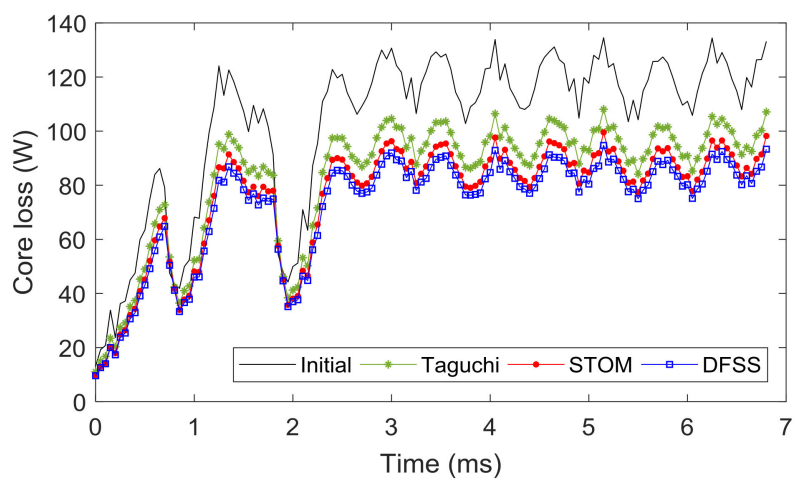

Figure 13. Core losses for the FSPMM with four designs.

Finally, considering the manufacturing quality of this motor in batch production, performance variations in terms of manufacturing tolerances (noise factors) are conducted for these four designs. Figures 14 and 15 illustrate the distributions of average torque and core loss given by the Monte Carlo analysis, respectively. As shown, the STOM and DFSS designs can ensure that all samples satisfy the two requirements, i.e., average torque higher than $2 \mathrm{Nm}$ and core loss lower than $130 \mathrm{~W}$. For the Taguchi parameter design, the minimal torque is less than $2 \mathrm{Nm}$, meaning that some (a small percentage) motors cannot meet this requirement in the batch production. Therefore, the motor performance and manufacturing quality of the FSPMM have been improved significantly by using the proposed STOM. 


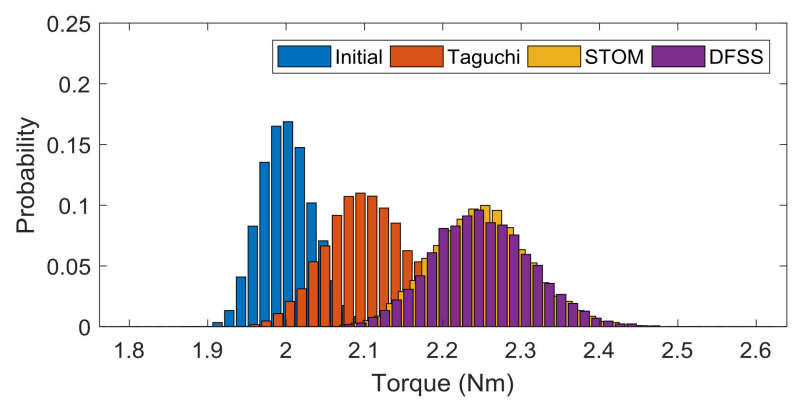

Figure 14. Distributions of output torque considering the manufacturing tolerances.

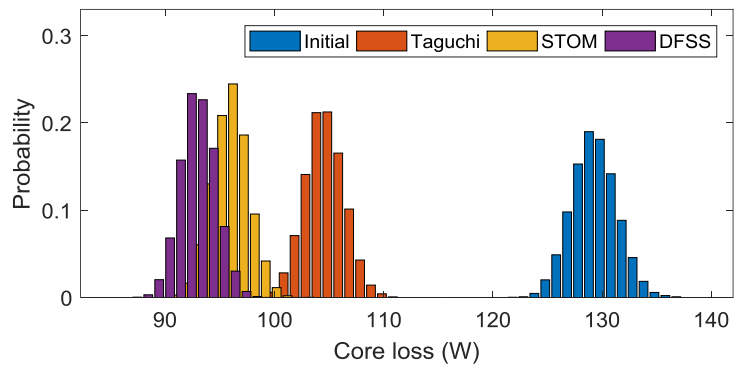

Figure 15. Distributions of core loss considering the manufacturing tolerances.

\section{Conclusions}

This work investigated the optimization of the manufacturing process and robust design of a low-cost FSPMM with SMC cores based on the Taguchi method. For the heat treatment in the manufacturing process, the Taguchi method was employed to identify the best combination of control factor levels. The relaxation temperature was found to be the most significant control factor to the magnetic properties of the SMC cores, and its best value is $500{ }^{\circ} \mathrm{C}$. This manufacturing method will benefit the low-cost batch production of SMC cores by using the molding technology. For the robust design of the FSPMM, manufacturing tolerances related to the ferrite PMs, SMC cores and the air gap were considered in the analysis. To obtain a robust design, Taguchi method was first employed, then a STOM was presented to further improve the motor performance and manufacturing quality. The STOM design was compared to the initial design, Taguchi design and DFSS design in terms of the motor performance, FEM computation cost, material cost and performance distributions considering manufacturing tolerances. It was found that the motor performance and manufacturing quality given by the optimal STOM design are close to those of the optimal DFSS design and are much better than those of the initial and Taguchi designs. Moreover, the required FEM computation cost of the STOM is less than $3 \%$ of that needed by the DFSS. Therefore, the proposed STOM is efficient.

The proposed method can be applied to other PM-SMC motors for low-cost applications. It can also be used as an effective method to improve the performance and manufacturing quality of other kinds of electrical machines. In the future work, several prototypes will be fabricated for this FSPMM with consideration of the manufacturing tolerances. Furthermore, more factors and their variations including material diversities will be investigated in the robust design of SMC and other kinds of motors.

Author Contributions: G.L. conceived the idea of the research, provided guidance and made the revision. C.L. and B.M. implemented the research, performed the analysis and wrote the draft. Y.G. and J.Z. provided supervision. All authors contributed significantly to this work.

Funding: This research was funded by the Hebei Province Education Department Youth Talent Leading Project under grant BJ2018037.

Conflicts of Interest: The authors declare no conflict of interest. 


\section{References}

1. Liu, C.; Lei, G.; Wang, T.; Guo, Y.; Wang, Y.; Zhu, J. Comparative study of small electrical machines with soft magnetic composite cores. IEEE Trans. Ind. Electron. 2017, 64, 1049-1060. [CrossRef]

2. Krings, A.; Boglietti, A.; Cavagnino, A.; Sprague, S. Soft magnetic material status and trends in electric machines. IEEE Trans. Ind. Electron. 2017, 64, 2405-2414. [CrossRef]

3. Kwon, Y.; Kim, W. Electromagnetic Analysis and Steady-State Performance of Double-Sided Flat Linear Motor Using Soft Magnetic Composite. IEEE Trans. Ind. Electron. 2017, 64, 2178-2187. [CrossRef]

4. Kim, C.; Jang, G.; Kim, J.; Ahn, J.; Baek, C.; Choi, J. Comparison of Axial Flux Permanent Magnet Synchronous Machines with Electrical Steel Core and Soft Magnetic Composite Core. IEEE Trans. Magn. 2017, 53, 1-4. [CrossRef]

5. Maloberti, O.; Figueredo, R.; Marchand, C.; Choua, Y.; Condamin, D.; Kobylanski, L.; Bommé, E. 3-D 2-D Dynamic Magnetic Modeling of an Axial Flux Permanent Magnet Motor with Soft Magnetic Composites for Hybrid Electric Vehicles. IEEE Trans. Magn. 2014, 50, 1-11.

6. Ishikawa, T.; Sato, Y.; Kurita, N. Performance of Novel Permanent Magnet Synchronous Machines Made of Soft Magnetic Composite Core. IEEE Trans. Magn. 2014, 50, 1-4. [CrossRef]

7. Ma, B.; Lei, G.; Zhu, J.; Guo, Y.; Liu, C. Application-oriented robust design optimization method for batch production of permanent magnet motors. IEEE Trans. Ind. Electron. 2018, 65, 1728-1739. [CrossRef]

8. Lei, G.; Liu, C.; Guo, Y.; Zhu, J. Multidisciplinary Design Analysis and Optimization of a PM Transverse Flux Machine With Soft Magnetic Composite Core. IEEE Trans. Magn. 2015, 51, 1-4. [CrossRef]

9. Ma, B.; Lei, G.; Zhu, J. Design, manufacturing and optimization of PM-SMC motors. In Proceedings of the 2017 7th International Electric Drives Production Conference (EDPC 2017), Wuerzburg, Germany, 5-6 December 2017; pp. 1-6.

10. Grande, M.; Ferraris, L.; Franchini, F.; Poskovic, E. New SMC Materials for Small Electrical Machine with Very Good Mechanical Properties. IEEE Trans. Ind. Appl. 2018, 54, 195-203. [CrossRef]

11. Lei, G.; Wang, T.; Guo, Y.; Zhu, J.; Wang, S. System level design optimization methods for electrical drive systems: Deterministic approach. IEEE Trans. Ind. Electron. 2014, 61, 6591-6602. [CrossRef]

12. Liu, C.; Lei, G.; Ma, B.; Wang, Y.; Guo, Y.; Zhu, J. Development of a New Low-Cost 3-D Flux Transverse Flux FSPMM with Soft Magnetic Composite Cores and Ferrite Magnets. IEEE Trans. Magn. 2017, 53, 1-5. [CrossRef]

13. Doering, J.; Steinborn, G.; Hofmann, W. Torque, Power, Losses, and Heat Calculation of a Transverse Flux Reluctance Machine with Soft Magnetic Composite Materials and Disk-Shaped Rotor. IEEE Trans. Ind. Appl. 2015, 51, 1494-1504. [CrossRef]

14. Hua, W.; Cheng, M.; Zhu, Z.; Howe, D. Analysis and optimization of back EMF waveform of a flux-switching permanent magnet motor. IEEE Trans. Energy Convers. 2008, 23, 727-733. [CrossRef]

15. Du, J.; Lu, P.; Liang, D. Optimal design of a linear transverse-flux machine with mutually coupled windings for force ripple reduction. IET Electr. Power Appl. 2018, 12, 271-280. [CrossRef]

16. Vukotić, M.; Miljavec, D. Design of a permanent-magnet flux-modulated machine with a high torque density and high power factor. IET Electr. Power Appl. 2016, 10, 36-44. [CrossRef]

17. Kim, S.; Lee, J.; Kim, Y.; Hong, J.; Hur, Y.; Jung, Y. Optimization for reduction of torque ripple in interior permanent magnet motor by using the Taguchi method. IEEE Trans. Magn. 2005, 41, 1796-1799.

18. Xia, C.; Guo, L.; Zhang, Z.; Shi, T.; Wang, H. Optimal Designing of Permanent Magnet Cavity to Reduce Iron Loss of Interior Permanent Magnet Machine. IEEE Trans. Magn. 2015, 51, 1-9. [CrossRef]

19. Hwang, C.; Chang, C.; Liu, C. A Fuzzy-Based Taguchi Method for Multiobjective Design of PM Motors. IEEE Trans. Magn. 2013, 49, 2153-2156. [CrossRef]

20. Song, J.; Dong, F.; Zhao, J.; Lu, S.; Dou, S.; Wang, H. Optimal design of permanent magnet linear synchronous motors based on Taguchi method. IET Electr. Power Appl. 2017, 11, 41-48. [CrossRef]

21. Dong, F.; Song, J.; Zhao, J.; Zhao, J. Multi-objective design optimization for PMSLM by FITM. IET Electr. Power Appl. 2018, 12, 188-194. [CrossRef]

22. Ishikawa, T.; Sato, S.; Takeguchi, S.; Matsuo, A. Design of a DC Motor Made of Soft Magnetic Composite Core by the Experimental Design Method. IEEE Trans. Magn. 2012, 48, 3132-3135. [CrossRef] 
23. Asama, J.; Oiwa, T.; Shinshi, T.; Chiba, A. Experimental Evaluation for Core Loss Reduction of a Consequent-Pole Bearingless Disk Motor Using Soft Magnetic Composites. IEEE Trans. Energy Convers. 2018, 33, 324-332. [CrossRef]

24. Potgieter, J.; Márquez-Fernández, F.; Fraser, A.; McCulloch, M. Effects Observed in the Characterization of Soft Magnetic Composite for High Frequency, High Flux Density Applications. IEEE Trans. Ind. Electron. 2017, 64, 2486-2493. [CrossRef]

25. Lei, G.; Zhu, J.; Guo, Y. Multidisciplinary Design Optimization Methods for Electrical Machines and Drive Systems; Springer: Berlin/Heidelberg, Germany, 2016; ISBN 978-3-662-49269-7.

26. Lei, G.; Zhu, J.; Guo, Y.; Liu, C.; Ma, B. A review of design optimization methods for electrical machines. Energies 2017, 10, 1962. [CrossRef]

27. Bramerdorfer, G.; Zăvoianu, A. Surrogate-based multi-objective optimization of electrical machine designs facilitating tolerance analysis. IEEE Trans. Magn. 2017, 53, 1-11. [CrossRef]

28. Wang, Q.; Niu, S.; Yang, L. Design Optimization of a Novel Scale-Down Hybrid-Excited Dual Permanent Magnet Generator for Direct-Drive Wind Power Application. IEEE Trans. Magn. 2018, 54, 1-4. [CrossRef]

29. Xiang, Z.; Zhu, X.; Quan, L.; Du, Y.; Zhang, C.; Fan, D. Multilevel design optimization and operation of a brushless double mechanical port flux-switching permanent-magnet motor. IEEE Trans. Ind. Electron. 2016, 63, 6042-6054. [CrossRef]

30. Zhu, X.; Shu, Z.; Quan, L.; Xiang, Z.; Pan, X. Multi-objective optimization of an outer-rotor V-shaped permanent magnet flux switching motor based on multi-level design method. IEEE Trans. Magn. 2016, 52, 1-8. [CrossRef]

31. Wang, Y.; Niu, S.; Fu, W. Sensitivity Analysis and Optimal Design of a Dual Mechanical Port Bidirectional Flux-Modulated Machine. IEEE Trans. Ind. Electron. 2018, 65, 211-220. [CrossRef]

32. Lei, G.; Zhu, J.; Guo, Y.; Shao, K.; Xu, W. Multiobjective sequential design optimization of PM-SMC motors for six sigma quality manufacturing. IEEE Trans. Magn. 2014, 50, 1-4. [CrossRef]

33. Lei, G.; Wang, T.; Zhu, J.; Guo, Y.; Wang, S. System-level design optimization method for electrical drive systems-robust approach. IEEE Trans. Ind. Electron. 2015, 62, 4702-4713. [CrossRef]

34. Lee, S.; Kim, K.; Cho, S.; Jang, J.; Lee, T.; Hong, J. Optimal design of interior permanent magnet synchronous motor considering the manufacturing tolerances using Taguchi robust design. IET Electr. Power Appl. 2014, 8, 23-28. [CrossRef]

35. Kim, K.; Jung, K.; Kim, J.; Hong, J.; Kim, S. Taguchi robust optimum design for reducing the cogging torque of EPS motors considering magnetic unbalance caused by manufacturing tolerances of PM. IET Electr. Power Appl. 2016, 10, 909-915. [CrossRef]

36. Omekanda, A. Robust torque and torque-per-inertia optimization of a switched reluctance motor using the Taguchi methods. IEEE Trans. Ind. Appl. 2006, 42, 473-478. [CrossRef]

37. Khan, M.; Husain, I.; Islam, M.; Klass, J. Design of Experiments to Address Manufacturing Tolerances and Process Variations Influencing Cogging Torque and Back EMF in the Mass Production of the Permanent-Magnet Synchronous Motors. IEEE Trans. Ind. Appl. 2014, 50, 346-355. [CrossRef]

38. Islam, M.; Islam, R.; Sebastian, T.; Chandy, A.; Ozsoylu, S. Cogging Torque Minimization in PM Motors Using Robust Design Approach. IEEE Trans. Ind. Appl. 2011, 47, 1661-1669. [CrossRef]

39. Lei, G.; Yang, G.; Shao, K.; Guo, Y.; Zhu, J.; Lavers, J. Electromagnetic device design based on RBF models and two new sequential optimization strategies. IEEE Trans. Magn. 2010, 46, 3181-3184. [CrossRef]

40. Lei, G.; Shao, K.; Guo, Y.; Zhu, J.; Lavers, J. Improved sequential optimization method for high dimensional electromagnetic optimization problems. IEEE Trans. Magn. 2009, 45, 3993-3996.

(C) 2018 by the authors. Licensee MDPI, Basel, Switzerland. This article is an open access article distributed under the terms and conditions of the Creative Commons Attribution (CC BY) license (http://creativecommons.org/licenses/by/4.0/). 